\title{
“Trabalhar para sempre. E sem drama": neoliberalismo e construções pedagógicas distópicas em Exame
}

\author{
"Work forever. And without drama": neoliberalism and dystopian pedagogical \\ constructions in Exame \\ “Trabajar para siempre. Sin drama”: neoliberalismo y construcciones pedagógicas \\ distópicas en Exame
}

DOI: 10.1590/1809-5844201827

\author{
Maria das Graças Pinto Coelho ${ }^{1}$ \\ https://orcid.org/0000-0002-6820-008X \\ Geilson Fernandes de Oliveira ${ }^{1}$ \\ http://orcid.org/0000-0002-3278-4044
}

${ }_{1}^{1}$ (Universidade Federal do Rio Grande do Norte, Centro de Ciências Humanas, Letras e Artes, Programa de Pós-Graduação em Estudos da Mídia. Natal - RN, Brasil)

\section{Resumo}

Compreendendo os discursos das mídias, a sua circulação na contemporaneidade e os diversos agenciamentos que deles ocorrem, analisa-se a construção discursiva em torno da temática do trabalho, espiando os ventos do neoliberalismo. O recorte empírico de análise é composto por duas edições da revista Exame, publicação voltada para o setor de negócios e economia que constrói narrativas sobre esta doutrina, mensalmente. Para tanto, faz-se uso dos pressupostos teórico-metodológicos da arquegenealogia foucaultiana, entendendo o discurso como prática que possui condições históricas e é atravessado por relações de saber e poder. Com efeito, constata-se que os discursos agenciados pela revista sobre o trabalho constituem-se como práticas sociais produtoras de sentidos, sociabilidades e subjetividades.

Palavras-Chave: Discurso das Mídias. Trabalho. Revista Exame. Sociabilidade. Neoliberalismo.

\begin{abstract}
Understanding the discourse of the media, their circulation in contemporary society and the different managements that occur as a result of them, we analyze the discursive construction around the theme of work nowadays, which shows the winds of neo-liberalism. The empirical analysis is made up of two editions of Exame magazine, a business and economics publication that develops narratives about this doctrine on a monthly basis. Using theoretical and methodological presumptions from Foucault's archeology, we can understand the discourse as a practice with historical conditioners that is permeated with relations of knowledge and power. The results show the discourses on work found in the magazine constitute social practices that produce meaning, sociability and subjectivities.
\end{abstract}

Keywords: Media Discourse. Work. Exame magazine. Sociability. Neoliberalism. 


\section{Resumen}

Comprendiendo los discursos de los medios, su circulación en la contemporaneidad y los diversos agenciamientos que de ellos ocurren, se analiza la construcción discursiva en torno a la temática del trabajo, espiando los vientos del neoliberalismo. El recorte empírico de análisis está compuesto por dos ediciones de la revista Exame, publicación volcada para el sector de negocios y economía que construye narrativas sobre esta doctrina, mensualmente. Para ello, se hace uso de los presupuestos teórico-metodológicos de la arquegenealogía foucaultiana, entendiendo el discurso como práctica que posee condiciones históricas y es atravesado por relaciones de saber y poder. En efecto, se constata que los discursos agenciados por la revista sobre el trabajo se constituyen como prácticas sociales productoras de sentidos, sociabilidades y subjetividades.

Palabras clave: El discurso de los medios. Trabajo. La revista Exame. Sociabilidad. El neoliberalismo.

\section{Introdução}

As discussões em torno da temática do trabalho enquanto atividade prático-social que faz parte da sociabilidade humana já possuem um largo rastro de pesquisas nas mais diversas áreas do conhecimento com várias interpretações consistentes (ENGELS, 1986; MARX, 1988; ANTUNES, 2005; GORZ, 2004, 2005). Todavia, mesmo frente a todo esse arcabouço interpretativo, os debates relativos ao tema continuam intensos na atualidade (SAFATLE, 2016; ANTUNES, 2014; BALTAR, 2010), haja vista se tratar de um fator de ordem social, o qual passa por transformações históricas que por hora se alimentam de um novo ciclo do capitalismo centrado em forças pró neoliberais. No Brasil, observa-se atualmente uma conjuntura econômica difícil, devido às mudanças estruturais na política econômica, à queda dos preços do petróleo e de outras commodities. A instabilidade político-econômica também coloca em xeque processos de mudança sobre a forma de se narrar o tema trabalho e seus axiomas, como emprego e relações trabalhistas. Resulta que as elites empresariais e as oligarquias políticas demonstram, na atualidade, uma grande capacidade para manipular, enganar e desorientar setores da população, graças à ajuda dos monopólios dos meios de comunicação. Para tanto, constroem narrativas que apelam por meio de receitas sentimentais, visando convencer a população a aceitar a vulnerabilidade dos postos de trabalho existentes, com baixo salário e proteção social.

Nesse ínterim, a mídia passa a construir narrativas não somente sobre o trabalho, mas acerca dos modos de consegui-lo, se comportar ou lidar com os seus desafios para atingir o sucesso. O jornalismo - um dos principais campos constitutivos da mídia e de seus discursos -, mobiliza esta temática com recorrência. No jornalismo de revista, gênero que tem na segmentação uma de suas características básicas (SCALZO, 2013), a questão tem comumente um tratamento especial, particularmente nas publicações voltadas para os negócios, economia e o próprio mundo do trabalho.

Com o objetivo de refletir sobre como o tema trabalho é discutido na mídia, a observação analítica se detém na construção discursiva sobre o tópico e suas fabulações, 
em um momento em que se acirram as discussões no que diz respeito ao seu aspecto onipresente, a extensão ou redução da carga horária, reforma da Previdência e redução dos direitos trabalhistas, entre outras implicações que acompanham os ventos das mudanças. Com efeito, elege-se como recorte empírico de análise duas edições da revista Exame, publicação quinzenal da editora Abril voltada para o setor de negócios e economia que vem construindo reiteradamente narrativas sobre o tema.

A escolha dessa publicação para análise justifica-se pelo amplo debate e circulação que promove sobre o trabalho. Já o recorte selecionado - duas edições, uma de outubro de 2012 e outra de janeiro de 2017 -, refere-se a repercussão que ambas tiveram em redes sociais (com uma grande multiplicação de memes, devido as abordagem sobre o tema); quanto por serem sintomáticas no que se refere a ótica pela qual a revista trata e elabora seus discursos sobre o trabalho. Considerando essa premissa, a observação de revistas com um espaço temporal distinto (quase 5 anos entre uma e outra) se justifica além da repercussão, pela necessidade de se analisar as possibilidades de mudanças no tratamento da questão do trabalho nesse intervalo de tempo, levando em conta, sobretudo, as transformações em torno da própria atividade laboral. Questiona-se, nesse sentido, não o porquê de a temática do trabalho ser apresentada de tal forma, mas como a sua representação se dá em cada edição, atentando para as suas condições de emergência, seus agenciamentos e relações de saber e poder.

A revista Exame é peça da marca Exame $^{1}$ da editora Abril e foi lançada no mercado editorial brasileiro no ano de 1967. Segundo o seu site, a publicação é apontada como “a maior e mais influente publicação de negócios e economia do país” e "possui circulação de cerca de 150.000 exemplares, sendo 115.000 assinaturas”. Além de poder ser adquirida através de assinaturas, também é possível encontrá-la em bancas de revistas - cada edição é vendida por R\$18,00 - e em plataformas online especializadas. Na seção “sobre” da revista, é afirmado que "segundo pesquisa do Instituto Ipsos-Marplan, a publicação é lida por 91\% dos presidentes das 500 maiores empresas instaladas no Brasil”2.

Como visto, trata-se de um periódico que tem como nicho editorial específico o segmento dos negócios e economia, fator que dá condições para a produção de discursos sobre o mundo do trabalho. Entretanto, mais do que publicizar discussões em torno deste contexto, observam-se agenciamentos que visam dar conta dos modos pelos quais as pessoas possam vivenciar o trabalho.

Para o estudo, seguem-se os pressupostos teóricos e metodológicos da arquegenealogia foucaultiana (FOUCAULT, 2013a, 2013b, 2011) para proceder as análises; compreendendo o discurso como uma prática que possui condições de possibilidades históricas, além de ser

1 Sob a marca Exame estão o site exame.com, a revista Exame e o anuário Melhores e Maiores, de acordo com o site da marca, o principal ranking financeiro das grandes empresas no país. Disponível em: <http://exame.abril.com.br/sobre/>. Acesso em: 02 jan. 2017.

2 As informações colocadas entre aspas neste parágrafo são apresentadas na seção 'sobre' da revista Exame. Disponível em: <http:// exame.abril.com.br/sobre/>. Acesso em: 02 jan. 2017. 
atravessada por relações de saber e poder. Nessa esteira, ressalta-se que os discursos sobre o trabalho na revista investigada constituem-se enquanto práticas produtoras de sentidos, sociabilidades e subjetividades. Por sua vez, o olhar analítico direciona-se especificamente para: 1) as capas, vistas como as vitrines em relação aos conteúdos que serão tratados no decorrer da revista como um todo, pois a sua função é justamente despertar a atenção dos leitores, convidá-los para a leitura e deleite daquilo que é prometido por meio do seu destaque e; 2) as matérias de capa.

É necessário ressaltar que o acesso franqueado às edições se deu a partir da plataforma de revistas digitais Go Read ${ }^{3}$, em funcionamento no Brasil desde outubro de 2016. Salientase que os conteúdos das revistas dispostas na plataforma são totalmente semelhantes às edições impressas em se tratando do texto, sendo a única diferença a presença de algumas poucas animações.

\section{Trabalho e sociabilidade}

Antes das análises propriamente ditas, pensa-se o constructo histórico sobre a noção de trabalho, para a partir disso chegar ao recorte empírico da análise, já trazendo o tema para a contemporaneidade.

De origem latina, a palavra “trabalho” advém do verbete tripalium, que caracterizava um instrumento utilizado na lavoura. No decorrer do século VI, passou a denominar o nome de um objeto de tortura. Observa-se que mesmo antes de ser associado a esse aspecto, o termo trabalho já era relacionado à perda da liberdade, uma vez que quem trabalhava na Roma Antiga eram os escravos, enquanto aqueles que eram mais abastados ficavam incumbidos de outras atividades, como a política. A partir do período do Renascimento, a questão vai ganhando novos contornos, especialmente com a formação dos Estados Nações e de seus sistemas econômicos, quando o trabalho ganha cada vez mais importância, sendo visto como algo enobrecedor e que possui uma função social. Com o desenvolvimento da urbanização e do comércio, as atividades laborais passam a ser mais valorizadas (ANTUNES, 2005).

Durante a Revolução Industrial, o trabalho passa a ser visto não apenas como um meio de produção, mas também uma função social, sendo identificado como uma forma em que as pessoas poderiam, a partir da venda de sua força de trabalho, satisfazer as suas necessidades, apesar disso ser incipiente, considerando, como propõe Marx (1984), que a relação entre a exploração dessa força e o pagamento por ela resulta na produção da maisvalia, não sendo o trabalhador recompensado como deveria, em detrimento da acumulação de riqueza dos empregadores.

3 A partir de uma assinatura mensal no valor de R $\$ 22,90$ - exceto no primeiro mês, que é grátis - o usuário pode ter acesso a mais de 100 títulos de revistas, que podem ser acessadas em computadores, tablets e smartphones. Disponível em: <https://www.goread.com. $\mathrm{br} /$ ?utm_source=google\&utm_medium=cpc\&utm_campaign=google_search\&gclid=CPr62rrPxtECFQgGkQodO94Puw>. Acesso em: 02 jan. 2017. 
De acordo com Engels (1986, p.35), o trabalho pode ser entendido como “a primeira condição básica para toda a existência humana, e isso numa tal extensão que, em determinado sentido, nós temos de dizer que o trabalho criou o próprio homem”. A acepção do teórico demonstra a importância do trabalho para a vida do homem em sociedade, ou mais do que isso, para a sua formação, pelo menos da forma como conhecemos e concebemos a noção de homem moderno.

Na teoria Marxista, o trabalho é concebido como uma relação estabelecida entre o homem e a natureza, a partir do qual são desencadeados processos de ação por parte do primeiro sobre a segunda, efetivando, a partir disso, modificações na constituição do próprio homem. Além disso, para Marx (1984, p.202), o trabalho é algo que está exclusivamente ligado ao homem. Em suas palavras, o trabalho é

[...] um processo de que participam o homem e a natureza, processo em que o ser com sua própria ação impulsiona, regula e controla seu intercâmbio material com a natureza [...], põe em movimento as forças naturais de seu corpo, braços, pernas, cabeça e mãos, a fim de apropriar-se dos recursos da natureza, imprimindo-lhes forma útil à vida humana. Atuando assim, sobre a natureza externa e modificando-a, ao mesmo tempo modifica sua própria natureza.

Neste sentido, a visão do trabalho na ótica de Marx (1984) pressupõe que a atividade laboral atua de forma direta na construção do sujeito trabalhador, o que pode ser estendido para as suas sociabilidades e subjetividades. Para Marx (1984, p.209), o trabalhador exerce o seu potencial de trabalho sob o controle do capitalista, de modo que é a este último a quem pertence o seu trabalho. O capitalista é o responsável pelos meios de produção e sempre busca que o trabalho seja realizado de acordo com os seus princípios, a fim de evitar o desperdício de matéria prima, visando atingir maior produtividade.

Marx (1984) afirmava que os modos pelos quais os indivíduos produzem as suas vidas materiais possuem uma relação direta com os modelos de desenvolvimento político, cultural e social. Dessa forma, identifica-se o trabalho como uma atividade sempre em transformação na história, conforme as condições de seu tempo de existência. Muitas mudanças significativas já ocorreram e continuam a ocorrer ${ }^{4}$ e, em nossos dias, evidenciase a sua passagem por novas rupturas ${ }^{5}$, o que possivelmente poderá desencadear outras

\footnotetext{
4 No Brasil, as mudanças mais contundentes são associadas à consolidação das Leis Trabalhistas na Era Vargas (1943), quando os direitos a um salário mínimo, jornada de oito horas, férias remuneradas, previdência social e descanso semanal se tornaram garantias. Recentemente, transformações significativas também tem se apresentado, por exemplo, por meio da extensão desses direitos aos trabalhadores e trabalhadoras domésticas (em vigor desde junho de 2015), que passam a ter suas profissões regulamentadas.

5 Como o que vem acontecendo com a aprovação da reforma trabalhista, em 2017, que altera diversos artigos da Consolidação das Leis Trabalhistas, com destaque para a terceirização dos serviços. Disponível em: <https://www25.senado.leg.br/web/atividade/materias/-/ materia/129049>. Acesso em: 07 jun. 2018.
} 
mudanças nas relações de produção dos sistemas econômicos da atualidade, refletindo diretamente nos trabalhadores e em suas formas de vida.

Considerando essa problemática, ressaltam-se as implicações que o trabalho possui para a construção das identidades dos sujeitos, bem como para as suas sociabilidades, no sentido de ser um dos aspectos ou pontos de ancoragem que marcam a noção de si mesmo perante os outros. Observando Simmel (1983), pode-se afirmar que a sociabilidade construída a partir das atividades laborais trata-se de uma forma, onde sociações se estabelecem. A sociação, por sua vez, diz respeito a um “[...] processo permanente do vira-ser da vida social, processo sempre in fieri, que está acontecendo sem que se possa dizer que já aconteceu” (SIMMEL, 1983, p.31). Com um caráter aberto e transitório, as sociações podem ser estabelecidas de diferentes maneiras e a partir de distintos territórios, não possuindo um fim em si mesma. Preceitos morais, modelos de governo, o modus operandi da sociedade, as condições de trabalho, entre muitos outros aspectos constituem-se como fontes para a sociabilidade. Torna-se imprescindível, assim, abordar essa relação pensando o modo de produção capitalista vigente, especialmente em meio à reestruturação produtiva e à crise do capital, fatores que tem indicado a (re)ascensão do neoliberalismo, provocando a desregulamentação e/ou flexibilização de leis trabalhistas, precarização do trabalho, a sua invasão na vida privada etc.

Essas mudanças estruturais, de ordem social e cognitiva, parecem se expandir em uma sociedade em que a informação e as relações são efetivamente mediadas e midiatizadas. Por meio de suas produções discursivas e sua grande circulação, na atualidade, a mídia coloca-se como uma instância agenciadora de sentidos acerca da problemática, fator que passa agora a ser analisado quando da reflexão de duas edições da revista Exame que trazem como chamada de capa o tema trabalho.

\section{“Trabalhar para sempre. E sem drama"}

As edições analisadas são, respectivamente, do ano de 2012 e 2017, como já mencionado. A primeira é a edição 1.027, ano 46, n.21, de 31 de outubro de 2012. Já a segunda é a edição 1.129, ano 51, n.1, de 18 de janeiro de 2017. 
Figuras 1 e 2: Capas Exame - outubro de 2012 e janeiro de 2017
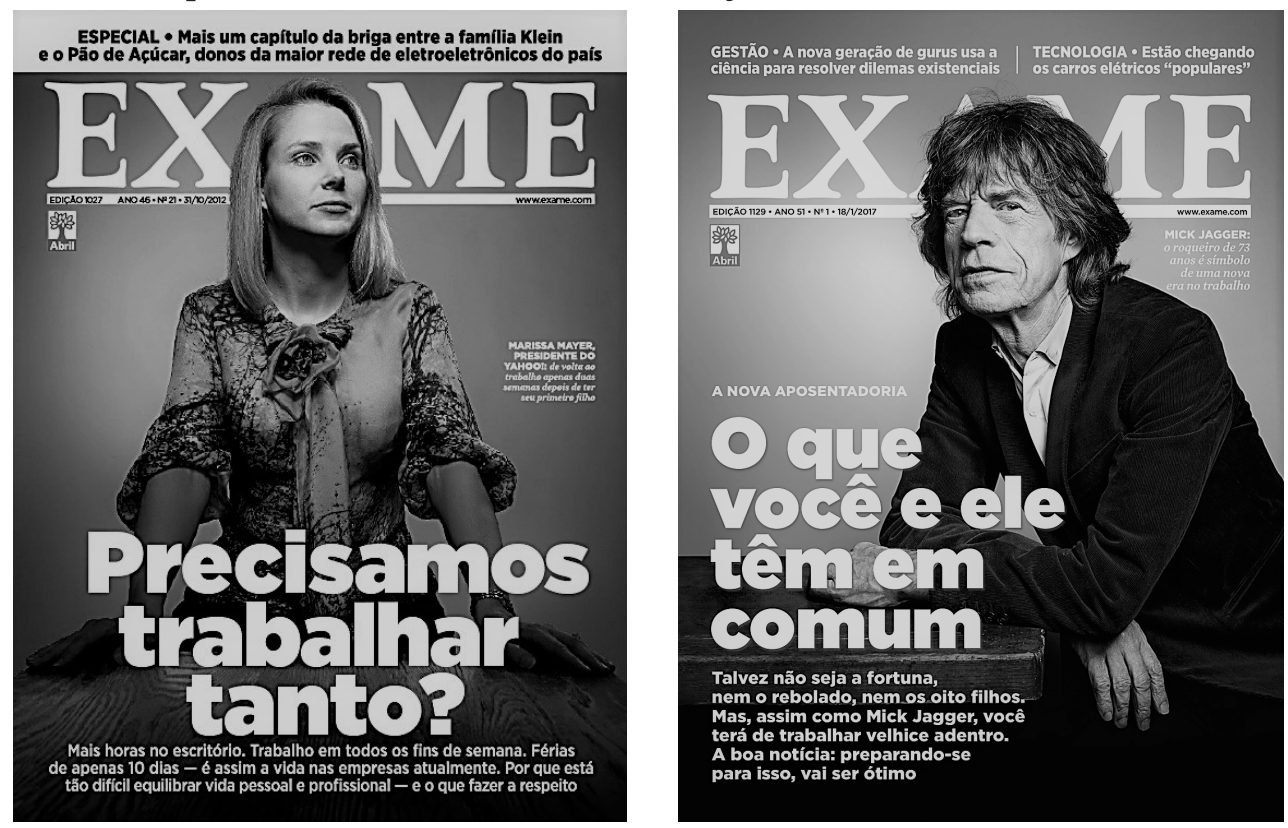

Fonte: Prints feitos pelos autores a partir do acesso à revista pelo Go Read.

Utilizando de uma composição estética semelhante (fundos em cores neutras, personagens centrais cuidadosamente posicionados e enunciados verbais chamativos), ambas as capas tematizam como aspecto central o trabalho.

Na primeira capa, se tem a figura de uma mulher ainda jovem com um olhar distante para o horizonte - provavelmente o futuro - ao mesmo tempo em que demonstra uma postura altiva e segura. Trata-se de Marissa Mayer, executiva americana presidente do Yahoo!. Como enunciado principal, se tem um questionamento corriqueiro em relação ao mundo do trabalho: “Precisamos trabalhar tanto?”. Logo abaixo, outro enunciado em tom afirmativo diz: "Mais horas no escritório. Trabalho em todos os fins de semana. Férias de apenas 10 dias - é assim a vida nas empresas atualmente. Por que está tão difícil equilibrar vida pessoal e profissional - e o que fazer a respeito" (CAPA EXAME, edição 1.027, 2012). Tais passagens, além de serem construídas de forma assertiva, parecem indicar de imediato o posicionamento da revista: o de construir uma vinculação com o sujeito leitor e se colocar como uma agente orientadora, uma vez que propõe, como observado ao final do segundo enunciado, o que fazer a respeito do ponto indicado, ou seja, como lidar com os complicados regimes de trabalho apresentados. Para tanto, a personagem que ilustra a capa não é uma pessoa aleatória, mas alguém que esteve "de volta ao trabalho apenas duas semanas depois de ter seu primeiro filho” (CAPA EXAME, edição 1.027, 2012) e possui experiências bem-sucedidas no manejo de situações delicadas. 
Já na edição 1.129, de janeiro de 2017, quem ilustra a capa é Mick Jagger, artista internacionalmente conhecido por liderar uma das bandas de rock de maior sucesso do planeta nos últimos anos, a Rolling Stones. Com os olhos direcionados para o leitor, Jagger é estrategicamente posto na capa para mostra o que você - o leitor, e ele - Mick Jagger, têm em comum, isto, em relação ao trabalho durante a velhice, o que poderá torna-se obrigatório no Brasil, caso os indicativos de mudança no sistema previdenciário - que conforme nova proposta do Governo busca estender o tempo de contribuição para a aposentadoria - sejam aprovados. Segundo a revista, o que o leitor e Jagger têm em comum "talvez não seja a fortuna, nem o rebolado, nem os oito filhos. Mas, assim como Mick Jagger, você terá de trabalhar velhice adentro. A boa notícia: preparando-se para isso vai ser ótimo" (CAPA EXAME, edição 1.129, 2017). Com efeito, de modo genérico, o leitor é então colocado pela revista em uma situação que, caso se efetive a reforma previdenciária, os tornará semelhantes a Jagger - com o trabalho velhice adentro. Afora esta comparação, a revista se coloca mais uma vez no lugar de perito do assunto e postula que se houver um preparo para isso, vai ser ótimo, discursivizando preceitos e agenciando estados de ânimo.

Não à toa, os personagens que ilustram ambas as capas são sujeitos de sucesso profissional, seja na juventude ou velhice, logo, exemplos a serem observados e seguidos. As posições-sujeito que assumem são relativas àquelas pessoas que a partir de determinado saber, conseguiram estar hoje em uma posição tão almejada. Em sua arquegenealogia, Foucault (2013a, 2013b, 2011) indica que o saber não existe sem o poder e vice-versa. Nos enunciados verbais e não verbais das capas, o saber obtido pelos personagens pode vir a ser apreendido pelo leitor a partir de alguns modelos prescritivos, alicerçados não só nas histórias de êxito no trabalho, mas em verdadeiros passos para o sucesso, os quais são descritos no desenrolar das matérias. Não diferente, esse saber que orienta, discursivizado pela revista, também é atravessado pelas relações de poder.

Pela breve descrição das capas, evidenciam-se abordagens que podem soar como contraditórias, já que, enquanto a edição de 2012 questionava o excesso de trabalho e como lidar com isso, a de 2017 parece defender justamente o prolongamento do tempo de trabalho. No entanto, uma vez analisadas as matérias das capas, o que se identifica é que ambas possuem um viés que não pode ser dissociado, o prescritivo.

Na edição de 2012, as matérias vinculadas à capa foram produzidas por Cristiane Mano, de Nova Iorque, e Patrícia Ikeda, de São Paulo. O conteúdo é dividido em duas partes, totalizando 20 páginas. A primeira, seguindo a linha do enunciado da capa, tem como título "qual é o limite” e o seu subtítulo diz o seguinte: “com jornadas de trabalho cada vez mais intensas, o equilíbrio entre uma trajetória profissional bem-sucedida e a vida pessoal se torna um objetivo tão almejado quanto distante. Mas, mesmo sem uma fórmula 
simples, há quem consiga se aproximar dele” (EXAME, edição 1.027, 2012, p.2²). Já a segunda matéria discorre sobre exemplos onde o equilíbrio entre trabalho e vida pessoal é mais fácil, como na Dinamarca, o que não ocorre no Brasil e em outros países, como os Estados Unidos, onde reside e trabalha a personagem da capa, que conseguiu chegar ao seu posto pela sua dedicação, mesmo sendo loira e linda, fato que chamou a atenção de muitos outros funcionários obstinados. O alcance de todo esse sucesso por Marissa, mesmo frente as dificuldades não foi fácil, assegura a revista, mas resultado de até 90h de trabalhos semanais, incluindo os sábados e domingos, o que proporcionou, apesar de todo o desgaste, resultados positivos, pois ela foi a primeira mulher engenheira a ser vice-presidente do Yahoo! e a mais jovem a se tornar presidente entre as 500 maiores companhias dos EUA.

A exceção (mulher, loira e linda) e o desafio (trabalho extenuante, o retorno apenas duas semanas após ter um filho) aparecem como marcas características do discurso construído sobre a trajetória de Marissa, evidenciando a perseverança como um fator que lhe é inerente. O saber que a levou aos altos escalões do poder no mundo dos negócios, dessa forma, foi instituído graças a sua dedicação extrema ao trabalho, trazendo à tona outros discursos, como o do enfrentamento às adversidades, impingindo por sua vez uma marca da meritocracia, verbete advindo do latim meritum - mérito, associada ao sufixo cracía - referente a poder, ou seja, o poder do mérito enquanto mecanismo de justificação da ascensão profissional. A identificação desse interdiscurso se apresenta como imprescindível para delimitar a formação discursiva analisada, partindo do pressuposto de que o discurso sempre é feito e refeito de diversos outros (inter)discursos, os quais permitem refletir não sobre o porquê dele se apresentar dessa forma, mas o que possibilita a sua emergência desse modo e não de outra (FOUCAULT, 2013a), desvelando, portanto, suas posições e mecanismo de poder.

O aumento expressivo da carga de trabalho, afora as vezes em que se leva trabalho para casa e não é colocado nesta conta (as 90h semanais formalmente trabalhadas), é posto como sendo algo que tem uma implicação positiva e direta para aqueles que buscam o sucesso no trabalho, tal qual foi para Marissa. Essa “é a nova regra do jogo”, diz Betânia Tanure, consultora que é fonte para a construção da matéria e da narrativa que vai sendo construída. Conforme Tanure, “o trabalho cada vez mais requer dedicação extrema” (EXAME, edição 1.027, 2012, p.3), o que resulta em um maior número de horas trabalhadas e é enunciado pela Exame como algo que tem bons motivos: “[...] estamos trabalhando como nunca. Até por bons motivos, diga-se. O ambiente de negócios mais vivo contribuiu para agitar o dia-a-dia dos executivos brasileiros” (EXAME, edição 1.027, 2012, p.5), mesmo que isso cause achatamentos na agenda pessoal ou a onipresença do trabalho, pois "a compensação financeira também passou a ser mais generosa” (EXAME, edição 1.027, 2012, p.5).

6 Como o acesso à revista se deu pelo Go Read, observou-se que a numeração das páginas era distinta em relação a revista impressa, de modo que na plataforma digital a numeração sempre era reiniciada a cada nova sessão da revista. Aqui, a paginação que utilizamos para referenciar as citações retiradas da Exame correspondem a versão digital. 
Nesta perspectiva, o jornalismo de revista da Exame é moldado por um viés pedagógico, buscando, a partir de seus discursos, agenciar os modos pelos quais os sujeitos devem proceder e estar no mundo. Para isso, faz uso da voz de especialistas, sujeitos detentores do saber verdadeiro e legitimado (FOUCAULT, 2013b; 2011) para tratar da problemática, as quais coadunam para a coerência da narrativa construída, reforçando-a. "A nova regra do jogo", “compensação financeira" e "bons motivos" podem ser os enunciados que melhor caracterizam a posição da revista em relação ao trabalho. Além das fontes especializadas, empresários (o saber da experiência, superação e sucesso) dão seus depoimentos e reforçam que apesar das dificuldades e possíveis complicações para a vida pessoal, o trabalho vale a pena, tendo em vista as suas compensações. As posições assumidas por estes sujeitos assemelham-se, então, ao da personagem de capa, Marissa, projeções inspiradoras de produtividade e satisfação.

Em certo momento, a revista até chega a argumentar que o excesso de trabalho pode acarretar problemas na vida pessoal - términos de relacionamentos, não ter uma relação próxima com os filhos e outros familiares; e na saúde - ansiedade, insônia etc., dando margem para o ocorrência de dissensos ou batalhas discursivas para a construção do sentido (GREGOLIN, 2003, p.2). Todavia, contornando essa prerrogativa, são acionados exemplos para lidar com determinadas situações de dificuldade, como no caso do presidente da operadora de telefonia Nextel, Sérgio Chala, que encontrou, como uma forma de reduzir a ansiedade, dedicar 45 minutos diários para a meditação. Os relatos trazidos acabam por construir uma narrativa sem maiores contradições, apesar de demonstrarem outros (inter) discursos (o cuidado consigo, necessidade de manter uma rede afetiva), os quais são utilizados com a finalidade de reforçar e naturalizar o que é dito. Trata-se da operação que envolve o controle e a exclusão do que pode ser dito. Entra em cena, assim, a ordem dos discursos (FOUCAULT, 2011) expressa pelo espaço dado a um único viés - a extensão do trabalho como algo corriqueiro, positivo e produtivo, ao mesmo tempo em que qualquer posição contrária é interditada e colocada fora da ordem do discurso da revista.

O equilíbrio entre trabalho e vida pessoal, segundo a revista, está na disciplina. Uma forma de disciplina que não diz respeito necessariamente à redução do trabalho, mas a uma autodisciplina que dê conta dele e da vida pessoal. A resposta a ser tecida a partir do questionamento inicial - precisamos trabalhar tanto? - parece, então, ser sim, desde que com disciplina para saber lidar e se autogerir no trabalho e nas outras formas de convívio social, silenciando outras possibilidades e formas de vida, como se aquela fosse não somente comum, mas a mais satisfatória. Na tensão analítica, percebe-se que apesar de construir uma narrativa que pretensamente busca questionar a carga-horária de trabalho nas matérias de capa da edição 1.027, de outubro de 2012, a Exame mais do que problematizar a questão, parece reforça-la, mostrando a dedicação ao trabalho como o caminho para o sucesso. Verifica-se, assim, o prisma neoliberal adotado pela revista, defendendo uma 
autorregulação e motivando uma sociabilidade empreendedora e autogerida para lidar com situações adversas.

O neoliberalismo diz respeito ao resgate, em meados do século XX, dos ideais liberais que sustentaram teórico e intelectualmente a emergência do capitalismo. Em um primeiro momento, seria uma tentativa de retomada do liberalismo clássico - livre concorrência e iniciativa, a propriedade privada etc. (MORAES, 2001). O seu desenvolvimento, contudo, não ocorreu conforme planejado inicialmente e o seu destino acabou por ser bem diferente daqueles ideais que emergiram quando da ascensão da burguesia, iluminismo e revolução francesa - bases das ideias liberalistas. A nova corrente buscou, por seu turno, dar respostas a crise capitalista ocorrida em 1929, indo na contramão do estado de bem-estar social.

Conforme Moraes (2001, p.17), no Brasil, a política neoliberal tem início com a abertura comercial do governo Collor, tendo prosseguimento nos governos de Itamar Franco e Fernando Henrique Cardoso. Para alguns intelectuais, a adoção do sistema neoliberal - que promoveu a privatização de grandes empresas e a livre circulação comercial - significou um desastre para a cadeia produtiva nacional, pois muitas empresas locais acabaram fechadas haja vista a forte concorrência estrangeira. No campo do trabalho, provocou a precarização, flexibilização em suas leis, a espoliação, desmonte do sindicalismo, entre outros fatores. Sob a égide do neoliberalismo, as discussões sobre a jornada de trabalho - tema abordado nos discursos analisados - mostram-se como um verdadeiro campo de batalhas, pois a produção passa a ser mais extensiva e a força de trabalho mais explorada.

De acordo com Foucault (2008), o neoliberalismo pode ser entendido como uma racionalidade de governo. Visto dessa forma, indica uma prática em que se encontram uma boa adequação e articulação dos princípios de governo, das técnicas de poder e da conduta dos próprios indivíduos. Entendida como uma ação orientada racionalmente para determinado fim (COHN, 2003, p.231), essa racionalidade proclama para si a valorização das liberdades individuais, reclamando uma economia dotada de processos autônomos e espontâneos. Essas particularidades têm implicações diretas nas relações sociais e nos próprios sujeitos, afirma Foucault (2008). Para ele, a imagem do indivíduo neoliberal pode ser definida por práticas que revelam um sujeito que busca a maior probabilidade de ganhos, calculando as suas ações para obtenção de rendimentos cada vez maiores. Conforme a ética neoliberal, o sujeito é colocado como alguém que deve ser empreendedor, um capital que requer investimentos contínuos, de modo a ser treinado ou buscar treinamentos para conseguir lidar com as mais diversas atribuições, seja da vida pública ou particular. Este modelo é enunciado pela Exame, que o media e o coloca como forma de sentir, pensar e agir em relação ao trabalho.

Para Couldry (2008, p.25), o neoliberalismo trata-se de “[...] um modo particular de organização socioeconômica construído em torno da primazia dos mercados [...]”. Em sua visão, os discursos baseados nesse sistema econômico operam por meio do sentido de senso 
comum, colocando a disciplina do sujeito como caminho para o equilíbrio entre trabalho e vida pessoal. Apesar de iminentemente social, suas práticas são naturalizadas a fim de legitimar o mercado e desvalidar qualquer crítica. Referente a pretensa naturalidade e isenção - modos pelos quais o neoliberalismo se apresenta e é enunciado, vale retomar Foucault (2013b) e a sua discussão sobre as relações de poder, pois, como ele assevera, a mais densa concentração de poder está justamente naquilo que é dado como comum ou natural.

A Exame faz uso de estratégias de saber e poder que ecoam a ética do neoliberalismo. Nas suas práticas discursivas, o controle e a disciplina são recorrentemente objetivados a fim de produzir modelos de sociabilidades e subjetividades performativas sobre o trabalho como algo natural. O sucesso ou fracasso do sujeito passa a ser resultante unicamente do seu esforço - ou a sua falta -, independente das condições socioeconômicas em curso, fortalecendo o pensamento empreendedor, autônomo e meritocrático e compondo o desenho das subjetividades neoliberais: flexíveis, supostamente livres e capazes de governar a si mesmo autonomamente (FOUCAULT, 2008). Apesar de sua composição e temporalidade distinta, esse viés também é apresentado na edição 1.129, de 2017, quando a temática do trabalho é retomada a partir das discussões em torno do aumento do tempo de trabalho necessário para a aposentadoria no Brasil, tendo como base a proposta do Governo Federal de mudança na idade mínima e tempo de contribuição ${ }^{7}$.

A aprovação da Proposta de Emenda à Constituição (PEC) - número 287/2016, referente a Reforma da Previdência já passou pela análise da Comissão de Constituição de Justiça (CCJ) da Câmara dos Deputados no fim do mês de dezembro de 2016 e foi aprovada após alterações. O passo seguinte seria a sua votação no Plenário da Câmara, porém, após algumas tentativas sem sucesso, a proposta foi temporariamente suspensa em fevereiro de 2018, haja vista o Decreto que prevê a Intervenção na área de segurança do Estado do Rio de Janeiro, cuja vigência (até 31 de dezembro de 2018) impede, por força da lei, que qualquer reforma seja aprovada. A despeito das manifestações populares contrárias ${ }^{8}$, o governo justifica a necessidade de reformas em razão do aumento da expectativa de vida dos brasileiros, levando em conta ainda a tendência de redução da população economicamente ativa, defendendo as mudanças como de suma importância para o equilíbrio das finanças da União.

Apesar de ainda se apresentar em tramitação, caso essas modificações sejam aprovadas, a Exame sugere que os brasileiros terão algo em comum com o astro do rock Mick Jagger: o fato de trabalharem durante a velhice, o que segundo a revista é uma tendência planetária, alinhando o seu pensamento às forças políticas no poder. Jagger e os Rolling Stones, assegura a publicação, são “[...] símbolos de uma era em que o trabalho

7 Ver mais informações sobre as mudanças propostas. Disponível em: <http://www.previdencia.gov.br/wp-content/uploads/2016/12/ Perguntas-e-Respostas.pdf $>$. Acesso em: 08 jul. 2018.

8 Pesquisa realizada pelo Palácio do Planalto em janeiro de 2018 mostra que apenas 14\% da população é favorável a Reforma da Previdência. Disponível em: < https://www1.folha.uol.com.br/mercado/2018/01/1954879-pesquisa-do-planalto-mostra-14-a-favor-da-reforma-da-previdencia.shtml>. Acesso em: 04 mar. de 2018. 
pode avançar velhice adentro” (EXAME, edição 1.129, 2017, p.1). A discussão sobre o tempo de trabalho é, de diferentes formas, tema das edições de 2012 e 2017. Relativo a isso, Thompson (1967) argumenta que o tempo continua ainda a ser o mais extenso foco de conflito nas relações de trabalho.

“Trabalhar para sempre. E sem drama”, enunciado que intitula este tópico é o mesmo que enuncia a matéria de capa da edição 1.129, de 2017. Ligado a uma rede de sentidos mais ampla, tendo em vista que o significado nunca é dado de forma isolada ou neutra, a enunciação do título corrobora os sentidos do trabalho para a Exame, reforçando o seu posicionamento a partir do tratamento explicitado. A sua abordagem é semelhante à da edição 1.027, de 2012, pois em ambas o trabalho é colocado como força motriz para o desenvolvimento não só da economia, mas do próprio sujeito - um autodesenvolvimento ou autoprodução, explicitando o viés nitidamente neoliberal.

Couldry (2008) classifica o neoliberalismo como um sistema de crueldades, o qual como todo sistema de crueldade, requer o seu próprio teatro. Com isso, performances ritualizadas são construídas como uma forma de legitimação desse sistema (COULDRY, 2008, p.25). Identificam-se estes modelos performáticos - de sucesso, felicidade e realização pessoal e profissional, mesmo trabalhando 90h semanais ou durante a velhice - na Exame, o que demonstra a sua vontade de verdade (FOUCAULT, 2013b) sobre as relações entre trabalho e vida social.

Se encontrar o equilíbrio entre trabalho e vida pessoal através da (auto)disciplina dos sujeitos era a chave do sucesso na edição de 2012, agora, trabalhar é apontado também como uma fonte da felicidade após os 65 anos - "Cada vez mais aposentados estão descobrindo que não é preciso viver na praia para ser feliz depois dos 65 anos. Saiba como chegar lá” (EXAME, edição 1.129, 2017, p.1), como é postulado no subtítulo da matéria de capa de 2017, produzida por Giuliana Napolitano, Luciano Pádua e Patrícia Vale. O ideal de receituário é novamente colocado em ação, remetendo a concepção de jornalismo de autoajuda, termo cunhado por Freire Filho (2011) para referir-se as produções midiáticas do território do jornalismo que visam diretamente as subjetividades dos consumidores, geralmente voltadas para a obtenção de ganhos imediatos, seja em matéria de adaptação social ou ascendência profissional.

Com enunciados sedutores, fator propiciado pelas afirmações assertivas, são construídos modelos de sociabilidades pautadas no incremento excessivo do trabalho, aspecto posto como engrandecedor, sinônimo de pessoas bem-sucedidas, destituindo outras fontes de experiência para a formação do sujeito. Jagger, nesse sentido, é colocado como um exemplo a ser seguido, pois ele está trabalhando aos 73 anos e adorando, afirma a matéria, mesmo sem ter realizado nenhuma entrevista com o artista, o que configura uma postura, no mínimo, contraditória em termos de coerência, uma vez que é justamente o cantor quem ilustra a prerrogativa defendida pela edição. Outros profissionais que trabalham com 
idades mais avançadas também dão os seus depoimentos. Todos, salienta-se, continuam trabalhando por vontade própria, como ocorre com Mick Jagger. Muitos já são, inclusive, aposentados. Nenhuma das fontes trabalha por obrigação do Estado, o que se mostra como incongruente para a narrativa, alicerçada em uma posição discursiva atrelada às propostas do Governo para a Reforma da Previdência.

É certo que a revista se direciona a um público mais abastado economicamente, o que possibilita a presença de sujeitos sempre ligados às grandes empresas, mas em uma edição que trata do trabalho e aposentadoria, defendendo mudanças significativas para a Previdência, generaliza os casos e a crença de que trabalhar após a velhice seja uma questão de escolha por parte da população brasileira, elaborando um discurso distópico, pois ao tratar do Brasil e de seu povo de uma forma homogênica, não possibilita um reconhecimento de uma realidade marcada por disparidades.

Estrategicamente, a própria velhice é ressignificada, assim como a concepção de juventude - "Se passar pelo Congresso [a Proposta de Reforma], será dificílimo ver jovens de 50 anos aposentados, como acontece hoje [...]” (EXAME, edição 1.129, 2017, p.5), promovendo um novo valor de uso desses sujeitos para o capital por meio do prolongamento da venda de suas forças de trabalho. De modo breve, a Exame chega a mencionar que "[...] é complicado seguir adiante em trabalhos que exigem esforço físico ou implicam uma rotina extenuante de viagens e reuniões. Quem não se preparou para mudar de emprego, ou mesmo de profissão, poderá ficar num beco sem saída” (EXAME, edição 1.129, 2017, p.8), afirma. Enquanto possibilidade de contradição, como ocorreu na edição de 2012, o argumento é logo suprimido e algumas prescrições para o preparo e gestão dos desafios são elencadas, reforçando a concepção de um jornalismo de autoajuda. A receita prescrita demonstra mais uma vez a rubrica do modelo neoliberal, já que é voltada unicamente para o sujeito que deve além de estar aberto e flexível às mudanças, se disciplinar para poder superá-las. Em nenhum momento, o auxílio ou intermédio do Estado é mencionado.

Valores e representações são moldados pela narrativa da revista, engendrando certos tipos de relações sociais e interditando outras por meio de seus silêncios (FOUCAULT, 2011). Logo, são (re)produzidas sociabilidades e subjetividades compatíveis com as necessidades e premissas do modo de produção neoliberal. A Exame apresenta um discurso que faz ao dizer como são - ou deveriam ser - as relações no mundo do trabalho. Ao descrevê-lo, prescreve comportamentos adequados ou desejáveis, a fim de gerenciar modos de ser e estar. A disciplina, chave indicada para o equilíbrio entre trabalho e vida pessoal na edição de 2012, mostra-se como uma saída também para a problemática enunciada na edição de 2017. Em ambas, a autogestão e o poder em si mesmo são mais do que chaves, mecanismos de sustentação discursiva. 


\section{Considerações finais}

As discussões sobre o tema do trabalho na revista Exame nortearam as reflexões apresentadas neste artigo. Tratando-se de uma publicação voltada para o mercado econômico e de negócios, as narrativas construídas e fabuladas reforçam a sua forte vinculação com os setores mais abastados da sociedade brasileira - velhas oligarquias políticas, agentes financeiros, empresários, proprietários de bens rurais e urbanos e rentistas -, principalmente quando se percebe que são narrativas além de pedagógicas - como é comum no jornalismo de revista e em outros produtos da mídia -, distópicas, uma vez que não dialoga com a sociedade como um todo, apenas com a elite empresarial e política. Seus enunciados não reconstituem os fatos sociais, mas os recontextualizam em variáveis de experimentos cognitivos performáticos que apelam para a subjetividade do cidadão, como se pudesse recolocar suas premissas discursivas relacionadas ao trabalho no lugar dos acontecimentos cotidianos e no centro da rede imaginária global.

Mesmo promovendo a análise de duas edições que possuem temporalidades diferentes, identificou-se uma continuidade de posições e narrativas, desvelando a ausência de heterogeneidade discursiva e argumentativa sobre os fatos retratados, bem como o distanciamento de suas representações no que se refere à maioria dos trabalhadores brasileiros, mesmo daquela que está nos grandes centros do mercado de trabalho. As representações discursivas construídas revelam cenas distópicas, repetem enunciados de ordem que em si são redundâncias dos ideais neoliberais. As figuras de capa, para se ter uma noção, nem sequer vivem no Brasil. Como reconhecê-las, assim como os seus estilos de vida e associá-las ao contexto local? Conforme a narrativa convergente das edições, a resposta para esse questionamento só pode estar no próprio sujeito e no seu interesse não apenas em reconhecer Marissa e Jagger como personagens, mas possibilidades inspiradoras de sucesso que devem ser seguidas, seja na juventude ou na velhice.

Os discursos das edições ora analisadas mostram-se como formas insidiosas minuciosamente costuradas e articuladas que o neoliberalismo parece ter encontrado para inserir-se em nosso imaginário e propagar seus pressupostos, silenciar as suas contradições e fomentar as suas práticas, o que na Exame é feito como se fosse algo comum e natural. Contudo, um olhar mais atento logo revela a presença de uma rede de poderes que busca dar forma aos modos de viver o mundo do trabalho e constituir as sociabilidades e subjetividades dele decorrentes.

\section{Referências}

ANTUNES, R. (Org.). Os sentidos do Trabalho. Ensaio sobre a afirmação e a negação do trabalho. São Paulo: Boitempo, 2005.

Riqueza e miséria do trabalho no Brasil. São Paulo: Boitempo, 2014. 
BALTAR, P. et al. Moving towards decent work. Labour in the Lula government: reflections on recent Brazilian experience. Global Labour University, Working Papers, v.9, 2010.

COHN, G. Crítica e resignação: Max Weber e a teoria social. São Paulo: Martins Fontes, 2003.

COULDRY, N. Reality TV, ou o teatro secreto do neoliberalismo. In: COUTINHO, E. G.; FREIRE FILHO, J.; PAIVA, R. (Orgs.). Mídia e poder: ideologia, discurso e subjetividade. Rio de Janeiro: Mauad X, 2008.

ENGELS, F. Sobre o papel do trabalho na transformação do macaco em homem. Karl Marx \& F. Engels, Obras escolhidas. São Paulo, Alfa-Omega, v.2, 1986.

FOUCAULT, M. O nascimento da biopolítica. São Paulo: Martins Fontes, 2008.

A ordem do discurso. 21.ed. São Paulo: Loyola: 2011.

A arqueologia do saber. 8.ed. Rio de Janeiro: Forense Universitária, 2013a.

Microfísica do poder. 26.ed. São Paulo: Graal, 2013b.

FREIRE FILHO, J. O poder em si mesmo: jornalismo de autoajuda e a construção da autoestima. Revista Famecos, v.18, n.3. 2011.

GORZ, A. O imaterial: conhecimento, valor e capital. São Paulo: Annablume, 2005.

Misérias do presente, riqueza do possível. São Paulo: Annablume, 2004.

GREGOLIN, M. R. O acontecimento discursivo na mídia: metáfora de uma breve história do tempo.

(Org.). Discurso e Mídia: a cultura do espetáculo. São Paulo: Claraluz, 2003.

MARX, K. Salário, preço e lucro. São Paulo: Vértice, 1988.

O Capital - crítica da economia política. Livro I, tomo 2, 2ª ed. Rio de Janeiro: Bertrand Brasil, 1984.

MORAES, R. C. Neoliberalismo - de onde vem, para onde vai? São Paulo: Senac, 2001.

REVISTA EXAME. São Paulo, edição 1.027, ano 46, n.21, 31 out. 2012.

São Paulo, edição 1.129, ano 51, n.1, 10 jan. 2017.

SAFATLE, V. O trabalho do impróprio e os afetos da flexibilização. O circuito dos afetos: corpos políticos, desamparo e o fim do indivíduo. 2.ed. Belo Horizonte: Autêntica Editora, 2016.

SCALZO, M. Jornalismo de revista. 4.ed. São Paulo: Contexto, 2013.

SIMMEL, G. A natureza sociológica do conflito; a competição; conflito e estrutura de grupo; sociabilidade: um exemplo de sociologia pura ou formal. In: MORAIS FILHO, E. (Org.). Simmel. São Paulo: Ática. 1983.

THOMPSON, E. P. Time, work-discipline and industrial capitalism. Past \& Present, v. 38, 1967.

\section{Maria das Graças Pinto Coelho}

Possui pós-doutorado em Comunicação e Cultura pela Universidade Federal do Rio de Janeiro (UFRJ). Doutora em Educação pela Universidade Federal do Rio Grande do Norte (UFRN). Professora associada da UFRN e coordenadora do Programa de Pós-Graduação em Estudos da Mídia (PPGEM) e do Grupo de Pesquisa GEMINI - Grupo de Estudos da Mídia. Também é membro do Programa de Pós-Graduação em Educação (PPGE) da mesma instituição. E-mail: gpcoelho8@gmail.com. 


\section{Geilson Fernandes de Oliveira}

Doutorando em Estudos da Mídia pelo Programa de Pós-Graduação em Estudos da Mídia (PPGEM) da Universidade Federal do Rio Grande do Norte (UFRN). Mestre em Ciências Sociais e Humanas pela Universidade do Estado do Rio Grande do Norte (UERN). Especialista em Literatura e Ensino e em Gestão Pública pelo Instituto Federal de Educação, Ciência e Tecnologia (IFRN) e Universidade Aberta do Brasil (UAB). Graduado em Comunicação Social, Jornalismo, pela Universidade do Estado do Rio Grande do Norte (UERN). Membro do GEMINI - Grupo de Estudos da Mídia. E-mail: geilson_fernandes@hotmail.com.

Recebido em: 19.05.2017

Aprovado em: 15.07.2018 